\title{
Clinical impact of peroral endoscopic myotomy for esophageal motility disorders on esophageal muscle layer thickness
}

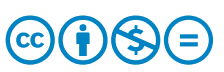

\author{
Authors \\ Institutions \\ 1 Division of Gastroenterology, Department of Internal \\ Medicine, Kobe University, Kobe, Japan \\ 2 Department of Gastroenterology, Kobe University \\ Hospital, Kobe, Japan
}

Daisuke Watanabe ${ }^{1}$, Shinwa Tanaka ${ }^{1}$, Fumiaki Kawara ${ }^{1}$, Hirohumi Abe ${ }^{1}$, Ryusuke Ariyoshi ${ }^{1}$, Yoshiko Nakano', Toshitatsu Takao', Yoshinori Morita', Takashi Toyonaga², Eiji Umegaki ${ }^{1}$, Yuzo Kodama'

submitted 28.6.2018

accepted after revision: 13.12 .2018

Bibliography

DOI https://doi.org/10.1055/a-0838-5268 |

Endoscopy International Open 2019; 07: E525-E532

(c) Georg Thieme Verlag KG Stuttgart · New York ISSN 2364-3722

Corresponding author

Shinwa Tanaka, Department of Endoscopy, Kobe University Hospital, 7-5-1 Chuo-ku, Kusunoki-cho, Kobe, Hyogo, 6500017, Japan

Fax: $+81-78-382-6309$

tanakas@med.kobe-u.ac.jp

\section{ABSTRACT}

Background and study aims Previously, we reported that esophageal muscle layer thickness was associated with technical complexity of peroral endoscopic myotomy (POEM). However, there are no data regarding the mid- term effects of POEM procedures on esophageal muscle layer thickness. Therefore, we conducted this study to elucidate mid-term effects of POEM procedures, and to examine whether postoperative changes in esophageal muscle layer thickness were related to particular clinico-pathological features in patients with esophageal motility disorders. Patients and methods Seventy-four consecutive patients with esophageal motility disorders who underwent POEM at Kobe University Hospital from April 2015 to December 2016 were prospectively recruited into this study. First, we investigated the esophageal muscle layer thickness values obtained at 1 year after POEM. Second, we evaluated the effects of a reduction in muscle layer thickness on various clinico-pathological features.

Results At 1 year after POEM, mean thickness of the inner circular muscle at $0 \mathrm{~cm}, 5 \mathrm{~cm}$, and $10 \mathrm{~cm}$ from the esophagogastric junction was $1.06 \pm 0.45 \mathrm{~mm}, 0.99 \pm 0.36 \mathrm{~mm}$, and $0.97 \pm 0.44 \mathrm{~mm}$, respectively. Among all sites, muscle layer thickness had significantly decreased after POEM. However, univariate logistic regression analysis demonstrated that no clinical factors were associated with esophageal muscle layer thickness after POEM procedure.

Conclusions We demonstrated for the first time that thickness of the esophageal muscle layer was significantly decreased after POEM. This result reveals that changes in esophageal muscle layer thickness caused by esophageal motility disorders are reversible.

\section{Introduction}

Esophageal motility disorders cause marked reductions in quality of life, as they can lead to severe dysphagia, regurgitation, and non-cardiac chest pain owing to a lack of coordinated esophageal motility function. According to the Chicago classification [1], these disorders are classified into the following major types: achalasia, esophagogastric junction (EGJ) outflow obstruction, distal esophageal spasm, and jackhammer esophagus. Among them, achalasia is the most common type of esophageal motility disorder (annual incidence: 1.63/100,000, prevalence rate: 10.82/100,000) [2]. Because pathogenesis of achalasia depends on impaired relaxation of the lower esophageal sphincter (LES) during swallowing [3], current treatments usually focus on the destruction or forced relaxation of the LES.

At present, peroral endoscopic myotomy (POEM) is one of the most important procedures for achalasia [4]. It is well known that this procedure produces a higher success rate than pneumatic balloon dilation (PD) [5], moreover, the fact that it is incision-less gives it an advantage over Heller myotomy. This is the reason why many advanced facilities use POEM to treat patients with esophageal motility disorders, and many articles regarding this technique have been published. Under these cir- 
cumstances, the efficacy and safety of POEM procedures have recently started to be elucidated.

Regarding short-term outcomes of POEM, we previously clarified associations between clinical outcomes and thickness of the esophageal muscle layer in patients who underwent POEM [6]. Esophageal muscle layer thickness was identified as the most important clinical factor affecting duration of POEM procedures. As for mid- and long-term outcomes of POEM, a few studies have suggested that a thick preoperative esophageal muscle layer might be a predictor of failure of PD [7]. Patients whose esophageal muscle layers were $<1.3 \mathrm{~mm}$ thick exhibited a significantly higher mid-term success rate after PD than those with thicker esophageal muscle layers (100\% vs. $36.3 \%, P=0.01)$. However, to the best of our knowledge, there are no data regarding mid- or long-term effects of POEM on esophageal muscle layer thickness.

Recently, POEM has been recognized as one of the standard treatments for achalasia, therefore, it has become an alternative to surgical myotomy. In addition, recent advances in medical imaging technology have enabled us to precisely evaluate the thickness of in vivo muscle layers preoperatively. Therefore, we conducted this study to elucidate mid-term effects of POEM procedures on thickness of the esophageal muscle layer, and moreover, we examined whether postoperative changes in esophageal muscle layer thickness are related to particular clinicopathological features in patients with esophageal motility disorders.

\section{Patients and methods}

\section{Study design and criteria}

To elucidate long-term effects of POEM on esophageal muscle layer thickness and associations between such changes and various clinicopathological features, we performed a prospective cohort study, involving patients with esophageal motility disorders who underwent POEM [8]. Before starting our study, sample size calculation was done. Prior data indicated that mean thickness of muscle layer was $1.6 \pm 0.7 \mathrm{~mm}$ [8], while that in patients without esophageal motility disorders was $0.61 \pm 0.1 \mathrm{~mm}$ ( $\triangleright$ Supplemental Fig. 1 ). With an average difference of 0.5 (half the mean difference between two groups based on the indicated values), standard deviation of 0.7 , probability of $\alpha$ error as 0.05 and probability of $\beta$ error as 0.8 , the required minimum sample size was estimated to be 31 patients. The sample size calculation was carried out using EZR version 1.37. This observational study was conducted at Kobe University Hospital with the approval of the institutional ethics committee. Written informed consent was obtained from all participants, and the study was carried out according to the Declaration of Helsinki.

\section{Patients}

First, 74 consecutive patients with esophageal motility disorders who complained of clinical symptoms and underwent POEM at Kobe University Hospital between April 2015 and December 2016 were prospectively recruited into this study [8]. Then, all patients who were eligible for 1 -year follow-up exam- inations were recommended to undergo upper gastrointestinal tract endoscopy and esophageal high-resolution manometry (HRM). Patients for whom insufficient data were available were excluded from the final analysis. The exclusion criterion for this study was patients who refused to or did not provide informed consent.

\section{Outcome measurements}

Prior to treatment, patients' symptoms were systematically documented via interviews. In addition, they underwent upper gastrointestinal endoscopy, barium esophagography, and HRM before POEM. Outcome measurements assessed in this study included thickness of the esophageal muscle layer, Eckardt symptom score, integrated relaxation pressure (IRP), POEM procedure-related variables (myotomy length, procedure time, and adverse events $[\mathrm{AE}]$ ), disease duration, type of achalasia, and previous treatments. Type of achalasia was evaluated using HRM according to the Chicago classification, version 3 [1]. Postoperative change in thickness of the esophageal muscle layer $(\triangle E M L T)$ was defined as reduction in thickness of the esophageal muscle layer noted after POEM, which was calculated as esophageal muscle layer thickness before POEM minus that seen at 1 year after the procedure. Overall success rate of POEM was defined as a post-POEM Eckardt score less than 2 or a reduction of more than 4 points from baseline [9]. All of the abovementioned variables were statistically analyzed.

\section{Indications for POEM and the POEM procedure}

All symptomatic patients were diagnosed with esophageal motility disorders were indicated for endoscopic POEM. All POEM procedures were performed in the operating room under general anesthesia. The POEM procedure was conducted as described previously [10], and it was carried out by two highly skilled endoscopists with experience of more than 30 POEM procedures.

\section{Endoscopic ultrasound evaluations}

All patients were included in the final analysis underwent endoscopic ultrasound (EUS) examinations before and 1 year after POEM. For the EUS examinations, a $20-\mathrm{MHz}$ miniature probe (UM-3R; Olympus Medical Systems, Tokyo, Japan) was used after filling the esophagus with de-aerated water. The EUS images were displayed on an EUS processing system (EU-ME2 premier plus; Olympus Medical Systems, Tokyo, Japan). All examinations were conducted under intravenous sedation. After the esophageal lumen had been filled with de-aerated water, the probe was positioned at the EG], and thickness of the esophageal muscle layer was measured at $0 \mathrm{~cm}, 5 \mathrm{~cm}$, and $10 \mathrm{~cm}$ above the EGJ, respectively. Images of the esophageal muscle layer that were obtained at maximum relaxation were selected.

\section{Symptom assessment}

Clinical symptoms were assessed according to the Eckardt score [11]. This score is calculated as the sum of the symptom scores for dysphagia, regurgitation, and chest pain (0: absent, 1: occasional, 2: daily, and 3: each meal) and weight loss score (0: no weight loss, $1: \leq 5 \mathrm{~kg}, 2: 5$ to $10 \mathrm{~kg}$, and $3: \geq 10 \mathrm{~kg}$ ). 


\section{Statistical analysis}

Mean, standard deviation, and range values were obtained for continuous variables, whereas ratios and percentages were obtained for categorical variables. Comparisons of continuous variables were performed using the Mann-Whitney $U$ test. Associations between the $\triangle E M L T$ and clinical factors were analyzed using univariate logistic regression analysis, and odds ratios (OR) were estimated and are shown together with $95 \%$ confidence intervals $(95 \% \mathrm{Cl})$. For this analysis, we classified eligible patients into two groups; i.e., into patients with $\triangle \mathrm{EMLT} \geq 0.45 \mathrm{~mm}$ and those with $\Delta \mathrm{EMLT}<0.45 \mathrm{~mm}$. Differences associated with $P$ values $<0.05$ were considered to be statistically significant, and all tests of significance were two-tailed. Cut-off values for each parameter in this study were determined by subjecting the mean value to rounding, where appropriate. All statistical analyses were conducted using JMP software, version 10.0.2 (SAS Institute, Cary, North Carolina, United States).

\section{Results}

Seventy-four consecutive patients with esophageal motility disorders were prospectively enrolled in this study ( $\triangleright \mathbf{F i g . 1}$ ) [8]. Among them, 64 patients completed 1-year follow-up examinations after undergoing POEM. However, 13 patients were excluded because of insufficient clinical information; therefore, 51 patients were included in the final analysis, as shown in $>$ Table 1 .

\section{Patient characteristics}

Of the 51 patients were eligible for the final analysis, 19 were male $(37.3 \%)$ and 32 female (62.7\%). Among all patients, mean age, body mass index (BMI), and disease duration were $52.0 \pm 16.7$ years (range: 16 to 85 ), $21.6 \pm 4.1$ (range: 15.8 to 31.6 ), and $6.6 \pm 12.9$ years (range: 0.5 to 31 ), respectively. Various subtypes of motility disorder exhibited the following frequencies: straight type, 42 patients (82.4\%); sigmoid type, four patients (7.8\%); advanced sigmoid type, two patients (3.9\%); and others, three patients (5.9\%). Most of the patients had not received any treatment prior to the POEM procedure (57 patients, $86.3 \%$ ).

\section{Procedure-related outcomes}

Among all eligible patients, mean procedure time and length of myotomy were $74.9 \pm 29.1 \mathrm{~min}$ (range: 44 to 179 ) and $13.9 \pm$ $4.0 \mathrm{~mm}$ (range: 5 to 20), respectively. Procedure-related AEs occurred in 11 patients $(11 / 51,21.6 \%$ ) ( Table 1$)$. Frequencies of these events were as follows (with some overlapping): pneumoperitoneum, eight patients (15.7\%); inadvertent mucosectomies, four patients (7.8\%); and subcutaneous emphysema, three patients (5.9\%). POEM procedure success was achieved in 49 of 50 patients (98.0\%). No serious complications or deaths occurred, and none of the adverse events required surgery.
74 patients were prospectively enrolled at the beginning of this study

\section{0 patients were lost to follow-up}

64 patients completed the 1-year follow up

5 patients did not undergo follow-up examinations

Data were insufficient to analyze in 8 patients

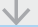

51 patients were included in the analysis

Fig. 1 Flow diagram of patients included in the analysis.

\section{Comparison of esophageal muscle layer thickness values obtained before and at 1 year after POEM}

- Table 2 and - Fig. 2 show a comparison of esophageal muscle layer thickness values obtained before and at 1 year after POEM. Before the procedure, mean thickness of the inner circular muscle (ICM) at $0 \mathrm{~cm}, 5 \mathrm{~cm}$, and $10 \mathrm{~cm}$ from the EGJ was $1.55 \pm 0.54 \mathrm{~mm}, 1.46 \pm 0.75 \mathrm{~mm}$, and $1.31 \pm 0.68 \mathrm{~mm}$, respectively. On the other hand, at 1 year after POEM, mean thickness of the ICM at $0 \mathrm{~cm}, 5 \mathrm{~cm}$, and $10 \mathrm{~cm}$ from the EGJ was $1.06 \pm$ $0.45 \mathrm{~mm}, 0.99 \pm 0.36 \mathrm{~mm}$, and $0.97 \pm 0.44 \mathrm{~mm}$, respectively. Therefore, our data showed that POEM significantly reduced thickness of the ICM at each esophageal site. However, thickness of the outer longitudinal muscle $(\mathrm{OLM})$ at $5 \mathrm{~cm}$ from the EG) did not change significantly after the procedure $(0.65 \pm$ $0.23 \mathrm{~mm}$ vs. $0.61 \pm 0.19 \mathrm{~mm}$ ).

\section{Comparison of the IRP and the Eckardt score at 1 year after POEM procedure between thick $(\geq 1.5 \mathrm{~mm})$ and thin $(<1.5 \mathrm{~mm})$ esophageal muscle layer groups}

To investigate whether effects of POEM on clinical factors differ among patients with and without thickened esophageal muscle layers, we compared clinical outcomes (the IRP and Eckardt score) of the thick $(\geq 1.5 \mathrm{~mm})$ and thin $(<1.5 \mathrm{~mm})$ esophageal muscle layer groups. In this analysis, IRP values and Eckardt scores obtained at 1 year after the POEM procedure did not differ significantly between the two groups ( $\triangleright$ Table 3 ).

\section{Comparison between $\triangle E M L T$ values of the ICM and OLM layers}

- Table 4 shows a comparison between $\triangle E M L T$ values of the ICM and OLM. In this analysis, $\triangle E M L T$ indicates reduction in thickness of the muscle layer observed after POEM. Mean $\triangle E M L T$ of the ICM at $0 \mathrm{~cm}, 5 \mathrm{~cm}$, and $10 \mathrm{~cm}$ from the EGJ were $0.48 \pm 0.52 \mathrm{~mm}, 0.47 \pm 0.84 \mathrm{~mm}$, and $0.35 \pm 0.59 \mathrm{~mm}$, respectively. On the other hand, mean $\triangle E M L T$ of the $O L M$ at $0 \mathrm{~cm}$, $5 \mathrm{~cm}$, and $10 \mathrm{~cm}$ from the EGJ were $0.18 \pm 0.47 \mathrm{~mm}, 0.04 \pm$ 
- Table 1 Baseline characteristics of patients treated with POEM.

Age, years old, mean \pm SD (range), n

$52.0 \pm 16.7(16-85), n=51$

Sex

- Male, n (\%)

$19 / 51(37.3 \%)$

- Female, n (\%)

$32 / 51(62.7 \%)$

BMI, mean \pm SD (range), n

$21.6 \pm 4.1(15.8-31.6), n=51$

Duration of disease, years, mean \pm SD (range), $n$

$6.6 \pm 12.9(0.5-31), n=51$

Type of achalasia, $n$

- Straight type (St), n (\%)

$42 / 51(82.4 \%)$

- Sigmoid type (Sg), n (\%)

$4 / 51(7.8 \%)$

- Advanced sigmoid type (A-Sg), n (\%)

$2 / 51(3.9 \%)$

- Others (JHE/DES/JHE + outflow), n (\%)

$3 / 51(5.9 \%)$

Previous treatment

- Pneumatic dilation (PD), n (\%)

$6 / 51(11.8 \%)$

- Heller myotomy (HM), n (\%)

$1 / 51(2.0 \%)$

- No previous treatment, $\mathrm{n}$ (\%)

$57 / 74(86.3 \%)$

POEM procedure time, min, mean $\pm S D$ (range), $n$

$74.9 \pm 29.1(44-179), n=51$

Length of myotomy, mm, mean \pm SD (range), $\mathrm{n}$

$13.9 \pm 4.0(5-20), n=51$

Adverse events, $\mathrm{n}(\%)$

$11 / 51(21.6 \%)$

Before POEM procedure

- Eckardt score, mean \pm SD (range), n

- Integrated relaxation pressure (IRP), $\mathrm{mmHg}$, mean $\pm \mathrm{SD}$ (range), $\mathrm{n}$

$5.9 \pm 2.1(2-10), n=51$

$29.4 \pm 13.4(2.3-75), \mathrm{n}=48$

After POEM procedure

- Eckardt score, mean \pm SD (range), $n$

$0.7 \pm 1.0(0-4), n=50$

- Integrated relaxation pressure (IRP), $\mathrm{mmHg}$, mean $\pm \mathrm{SD}$ (range), $\mathrm{n}$

$9.4 \pm 5.4(0.1-23.8), n=48$

POEM, peroral endoscopic myotomy; SD, standard deviation; BMI, body mass index; JHE, Jackhammer esophagus; DES, distal esophageal spasm; JHE+ outflow, Jackhammer esophagus plus esophagogastric junction outflow obstruction

$0.30 \mathrm{~mm}$, and $0.07 \pm 0.21 \mathrm{~mm}$, respectively. Thus, after POEM, the ICM exhibited significantly greater mean $\triangle E M L T$ than the OLM.

\section{Clinicopathological features associated with $\triangle E M L T$}

We evaluated the effects of a reduction in muscle layer thickness on various clinicopathological features. Results of the univariate logistic regression analysis are summarized in $\mathbf{~ T a b l e ~} 5$. In this analysis, age, sex, BMI, disease duration, type of achalasia, previous treatment, procedure time, length of myotomy, AEs, postoperative Eckardt score, and postoperative change in IRP level were found to have no significant influence on clinicopathological features at any of the examined esophageal sites.

\section{Discussion}

The number of myenteric neurons is decreased by achalasia, which results in impaired relaxation of the LES [12]. Because such functional obstruction can cause esophageal muscular hy- pertrophy $[13,14]$, we considered that thickness of the esophageal muscle layer might reflect clinical severity or symptoms of motility disorders. Recently, we examined associations between esophageal muscle layer thickness and various clinicopathological features [8]. In the latter study, we identified that a thick esophageal muscle layer was an independent predictor of a longer POEM procedure (OR: 8.00; $95 \% \mathrm{Cl}$ : 2.67-27.65, $P=0.0001)$. However, there were no significant differences in other clinical parameters between the thick and thin esophageal muscle layer groups. Therefore, we examined the midand long-term effects of POEM on esophageal muscle layer thickness in this study.

No previous studies have examined changes in esophageal muscle layer thickness that occur after treatment in patients with esophageal motility disorders. Previous studies based on visual $[15,16]$ or EUS examinations $[17,18]$ revealed that the muscularis propria of the esophagus usually thickens in patients with achalasia. In addition, several histological studies have assessed muscular pathology that arises in patients with 
- Table2 Comparison of esophageal muscle layer thickness values observed before and after POEM.

\begin{tabular}{|c|c|c|c|c|}
\hline & & Before POEM procedure & After POEM procedure & $P$ value \\
\hline \multirow[t]{3}{*}{ Inner circular muscle } & $0 \mathrm{~cm}$ from $\mathrm{EGJ}$, mean $\pm S D, \mathrm{~mm}$ & $1.55 \pm 0.54$ & $1.06 \pm 0.45$ & $<0.0001$ \\
\hline & $5 \mathrm{~cm}$ from $\mathrm{EG}$, , mean $\pm S \mathrm{D}, \mathrm{mm}$ & $1.46 \pm 0.75$ & $0.99 \pm 0.36$ & $<0.0001$ \\
\hline & $10 \mathrm{~cm}$ from $\mathrm{EG}$, , mean $\pm S D, \mathrm{~mm}$ & $1.31 \pm 0.68$ & $0.97 \pm 0.44$ & $<0.0001$ \\
\hline \multirow[t]{3}{*}{ Outer longitudinal muscle } & $0 \mathrm{~cm}$ from EGJ, mean $\pm \mathrm{SD}, \mathrm{mm}$ & $1.07 \pm 0.35$ & $0.89 \pm 0.34$ & 0.0069 \\
\hline & $5 \mathrm{~cm}$ from $\mathrm{EG}$, , mean $\pm S D, \mathrm{~mm}$ & $0.65 \pm 0.23$ & $0.61 \pm 0.19$ & NS \\
\hline & $10 \mathrm{~cm}$ from $E G]$, mean $\pm S D, \mathrm{~mm}$ & $0.60 \pm 0.19$ & $0.53 \pm 0.14$ & 0.0284 \\
\hline
\end{tabular}

POEM, peroral endoscopic myotomy; EG], esophagogastric junction; NS, not significant $(P>0.05)$
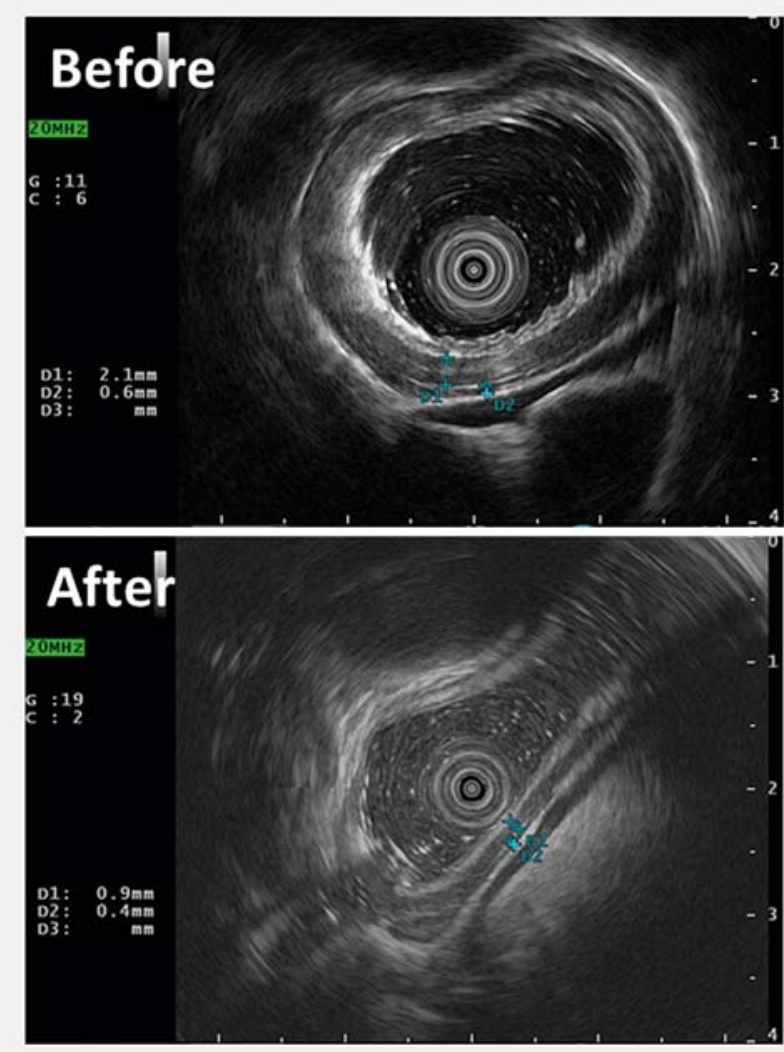

- Fig. 2 Representative image of esophageal muscle layer thickness before and at 1 year after POEM.

achalasia [19, 20]. Muscular hypertrophy was always seen at the LES and often extended up to the distal esophagus. Because functional obstruction can cause esophageal muscular hypertrophy, as mentioned above $[13,14]$, relieving such obstruction might lead to a reduction in the thickness of the esophageal muscle layer. The primary goal of treatment for achalasia is to disrupt the muscular components that contribute to LES pressure. Because POEM also aims to disrupt the LES, it should theoretically cause a reduction in LES pressure. Therefore, it should result in adequate relief of esophageal obstruction. In short, reducing LES pressure by performing POEM can ameliorate esophageal muscular hypertrophy, and therefore, should reduce thickness of the esophageal muscle layer. In accordance with this expectation, we clearly showed that thickness of the esophageal muscle layer was significantly decreased at 1 year after POEM.

In addition, we found that after POEM, the ICM displayed greater $\triangle$ EMLT values than the OLM $(P<0.001)$. There are two possible explanations for this. The first is that the balance between the ICM and OLM might be impaired in patients with esophageal motility disorders. In agreement with this, thickness of the esophageal muscle layer did not differ significantly between the ICM and OLM in patients without esophageal motility disorders ( $\triangleright$ Supplemental Fig. 1). On the other hand, in patients with esophageal motility disorders, the ICM was thicker than the OLM ( $\triangleright$ Table 2; ICM vs. OLM at $0 \mathrm{~cm}, 5 \mathrm{~cm}$, and $10 \mathrm{~cm}$ from the EG]; $P<0.01$ in each case). The difference between $\triangle E M L T$ values for the ICM and OLM might reflect the relative contributions of these muscles to pathogeneses of esophageal motility disorders. Therefore, the ICM might make a more significant contribution than the OLM to pathogeneses of esophageal motility disorders. The second possible reason for this finding is that it is due to characteristics of the POEM procedure itself. In the original POEM procedure [4], only the ICM bundles were subjected to endoscopic myotomy, leaving the OLM intact. We also perform selective myotomy of the ICM alone in POEM. Therefore, this might be the reason why we detected a significantly greater reduction in thickness of the esophageal muscle layer in the ICM than in the OLM.

In this study, we could not find any clinical factors that were associated with $\triangle$ EMLT. Although Li et al. previously claimed that thickness of the esophageal muscle layer on EUS before PD treatment was associated with mid-term treatment response and clinical symptoms [7], our study revealed that there were no significant differences in clinical outcomes between the thick and thin esophageal muscle layer groups. Compared with PD treatment, because POEM makes it possible to dissect muscular bundles completely while checking the endoscopic screen, both muscle tone abnormalities and other symptoms can be completely abrogated, regardless of the thickness of the esophageal muscle layer. Thus, the marked efficacy of the POEM procedure is considered to explain why no clinical factors were found to be associated with $\triangle E M L T$ in our study. However, our study had one patient ( $2 \%$ ) whose POEM procedure failed, 
- Table 3 Comparisons of IRP and the Eckardt score at 1 year after POEM between thick $(>1.5 \mathrm{~mm})$ and thin $(<1.5 \mathrm{~mm})$ esophageal muscle layer groups.

\begin{tabular}{|c|c|c|c|c|c|c|c|c|c|}
\hline & \multicolumn{3}{|c|}{$0 \mathrm{~cm}$ from $\mathrm{EG}]$} & \multicolumn{3}{|c|}{$5 \mathrm{~cm}$ from $\mathrm{EG}]$} & \multicolumn{3}{|c|}{$10 \mathrm{~cm}$ from $\mathrm{EGJ}$} \\
\hline & $\geq 1.5 \mathrm{~mm}$ & $<1.5 \mathrm{~mm}$ & $P$ value & $\geq 1.5 \mathrm{~mm}$ & $<1.5 \mathrm{~mm}$ & $P$ value & $\geq 1.5 \mathrm{~mm}$ & $<1.5 \mathrm{~mm}$ & $P$ value \\
\hline $\begin{array}{l}\text { IRP after } \mathrm{POEM}, \\
\text { mean } \pm \mathrm{SD}, \mathrm{mmHg}\end{array}$ & 10.2 & 8.4 & NS & 11.3 & 8.1 & NS & 7.7 & 10.1 & NS \\
\hline $\begin{array}{l}\text { Eckardt score after POEM, } \\
\text { mean } \pm \text { SD }\end{array}$ & 0.9 & 0.4 & NS & 0.7 & 0.7 & NS & 0.5 & 0.8 & NS \\
\hline
\end{tabular}

- Table 4 Comparison of $\triangle E M L T$ values between the inner circular and outer longitudinal muscle layers.

\begin{tabular}{|c|c|c|c|}
\hline & Inner circular muscle & Outer longitudinal muscle & $P$ value \\
\hline $0 \mathrm{~cm}$ from $\mathrm{EG}$, , mean $\pm \mathrm{SD}, \mathrm{mm}$ & $0.48 \pm 0.52$ & $0.18 \pm 0.47$ & 0.0003 \\
\hline $5 \mathrm{~cm}$ from $\mathrm{EG}$, mean $\pm \mathrm{SD}, \mathrm{mm}$ & $0.47 \pm 0.84$ & $0.04 \pm 0.30$ & $<0.0001$ \\
\hline $10 \mathrm{~cm}$ from $\mathrm{EG}$, mean $\pm S \mathrm{D}, \mathrm{mm}$ & $0.35 \pm 0.59$ & $0.07 \pm 0.21$ & $<0.0001$ \\
\hline
\end{tabular}

- Table 5 Univariate logistic regression analysis of clinical factors associated with a $\triangle E M L T$ value $\geq 0.45 \mathrm{~mm}$.

\begin{tabular}{|c|c|c|c|c|c|c|}
\hline \multirow[b]{2}{*}{ Variables } & \multicolumn{2}{|c|}{$\Delta E M L T$ at $0 \mathrm{~cm}$ from EGJ } & \multicolumn{2}{|c|}{$\Delta E M L T$ at $5 \mathrm{~cm}$ from $E G]$} & \multicolumn{2}{|c|}{$\Delta \mathrm{EMLT}$ at $10 \mathrm{~cm}$ from $\mathrm{EG}]$} \\
\hline & $\begin{array}{l}\text { Odds ratio } \\
\text { (95\% C. I.) }\end{array}$ & $\begin{array}{l}\text { Univariate } \\
P \text { value }\end{array}$ & $\begin{array}{l}\text { Odds ratio } \\
\text { (95\% C. I.) }\end{array}$ & $\begin{array}{l}\text { Univariate } \\
P \text { value }\end{array}$ & $\begin{array}{l}\text { Odds ratio (95\% C. } \\
\text { I.) }\end{array}$ & $\begin{array}{l}\text { Univariate } \\
P \text { value }\end{array}$ \\
\hline Age, $\geq 52$ vs. $<52$ yr & $1.25(0.41-3.81)$ & NS & $0.83(0.26-2.65)$ & NS & $0.49(0.14-1.58)$ & NS \\
\hline Sex, male vs. female & $1.43(0.46-4.54)$ & NS & $0.90(0.28-3.01)$ & NS & $1.13(0.34-3.98)$ & NS \\
\hline $\mathrm{BMI}, \geq 22$ vs. $<22$ & $0.48(0.14-1.58)$ & NS & $1.00(0.30-3.52)$ & NS & $0.41(0.12-1.37)$ & NS \\
\hline $\begin{array}{l}\text { Duration of disease, } \geq 7 \text { vs. } \\
<7 \text { years }\end{array}$ & $0.45(0.12-1.53)$ & NS & $1.13(0.32-4.29)$ & NS & $0.66(0.19-2.38)$ & NS \\
\hline $\begin{array}{l}\text { Type of achalasia, St type vs. } \\
\text { other types }\end{array}$ & $2.00(0.46-10.48)$ & NS & $1.60(0.35-7.00)$ & NS & $0.20(0.01-1.26)$ & NS \\
\hline Previous treatment, yes vs. no & $0.82(0.15-4.15)$ & NS & $0.69(0.13-3.88)$ & NS & $0.31(0.06-1.61)$ & NS \\
\hline Procedure time, $\geq 75$ vs. $<75$ & $0.66(0.21-2.00)$ & NS & $0.59(0.18-1.87)$ & NS & $1.43(0.44-4.78)$ & NS \\
\hline $\begin{array}{l}\text { Length of myotomy, } \geq 14 \mathrm{vs} \text {. } \\
14 \mathrm{~mm}\end{array}$ & $0.69(0.22-2.08)$ & NS & $0.68(0.20-2.15)$ & NS & $0.55(0.16-1.78)$ & NS \\
\hline Adverse events, yes vs. no & $0.92(0.23-3.55)$ & NS & $0.94(0.24-4.11)$ & NS & $0.84(0.21-3.69)$ & NS \\
\hline $\begin{array}{l}\text { Eckardt score after POEM, } \\
\geq 1 \text { vs. }<1\end{array}$ & $0.38(0.11-1.21)$ & NS & $0.98(0.30-3.31)$ & NS & $1.43(0.43-5.03)$ & NS \\
\hline$\Delta I R P, \geq 20$ vs. $<20 \mathrm{mmHg}$ & $1.39(0.43-4.59)$ & NS & $1.01(0.30-3.49)$ & NS & $1.27(0.37-4.60)$ & NS \\
\hline $\begin{array}{l}\text { The cut-off value for the } \triangle \text { EMLT wa } \\
\text { Two-tailed } P \text { values }<0.05 \text { were cor } \\
\text { EMLT, esophageal muscle layer thi } \\
\text { operative change in integrated rel }\end{array}$ & $\begin{array}{l}45 \mathrm{~mm} \text {. } \\
\text { ered to be statistically s } \\
\text { ess; EGJ, esophagogastr } \\
\text { ion pressure }\end{array}$ & $\begin{array}{l}\text { ificant. } \\
\text { junction; BMI, }\end{array}$ & mass index; $\mathrm{Cl}$, con & . & th significant $(P>0.05$ & P, post- \\
\hline
\end{tabular}

and in whom the $\triangle E M L T$ of the ICM at $0 \mathrm{~cm}, 5 \mathrm{~cm}$, and $10 \mathrm{~cm}$ from the EGJ were $0.7 \mathrm{~mm}, 0.1 \mathrm{~mm}$, and $0.1 \mathrm{~mm}$, respectively. These results indicate that there is a possibility that change of esophageal muscle layer thickness at the region other than LES correlate with failure of POEM. Therefore, more large-scale study might be useful to reveal the possible correlation of muscle thickness and response after myotomy.

This study had several limitations. First, esophageal muscle layer thickness measurements were operator-dependent and exhibited wide variation between different operators [21-23]. 
Second, the sample size was small, which resulted in the study having low statistical power. Third, the study was conducted at a single tertiary center, so the results might not be applicable to different institutions.

\section{Conclusion}

In conclusion, we demonstrated for the first time that thickness of the esophageal muscle layer was significantly decreased after POEM. Therefore, we consider that changes in thickness of the esophageal muscle layer caused by esophageal motility disorders are reversible. However, postoperative thickness of the esophageal muscle layer did not have any influence on outcomes of POEM.

\section{Acknowledgements}

The authors express their gratitude to Dr. Haruhiro Inoue.

\section{Competing interests}

None

\section{References}

[1] Kahrilas PJ, Bredenoord AJ, Fox M et al. The Chicago Classification of esophageal motility disorders, v3.0. Neurogastroenterol Motil 2015; 27: $160-174$

[2] Sadowski DC, Ackah F, jiang B et al. Achalasia: incidence, prevalence and survival. A population-based study. Neurogastroenterol Motil 2010; 22: e256-261

[3] Cassella RR, Brown AL Jr, Sayre GP et al. Achalasia of the esophagus: pathologic and etiologic considerations. Annals Surg 1964; 160: $474-487$

[4] Inoue H, Minami H, Kobayashi Y et al. Peroral endoscopic myotomy (POEM) for esophageal achalasia. Endoscopy 2010; 42: 265-271

[5] Pandolfino JE, Gawron AJ. Achalasia: a systematic review. JAMA 2015; 313: $1841-1852$

[6] Yoshizaki T, Toyonaga T, Tanaka S et al. Feasibility and safety of endoscopic submucosal dissection for lesions involving the ileocecal valve. Endoscopy 2016; 48: 639-645

[7] Li SW, Tseng PH, Chen CC et al. Muscular thickness of lower esophageal sphincter and therapeutic outcomes in achalasia: a prospective study using high-frequency endoscopic ultrasound. J Gastroenterol Hepatol 2018; 33: 240-248

[8] Watanabe D, Tanaka S, Ariyoshi R et al. Muscle layer thickness affects the peroral endoscopic myotomy procedure complexity. diseases of the esophagus Dis Esophagus 2018: 31

[9] Inoue $\mathrm{H}$, Sato $\mathrm{H}$, Ikeda $\mathrm{H}$ et al. Per-oral endoscopic myotomy: a series of 500 patients. J Am Coll Surg 2015; 221: $256-264$

[10] Tanaka S, Toyonaga T, Kawara F et al. Peroral endoscopic myotomy using FlushKnife BT: a single-center series. Endosc Int Open 2017; 5: E663-E669

[11] Eckardt VF, Aignherr C, Bernhard G. Predictors of outcome in patients with achalasia treated by pneumatic dilation. Gastroenterology 1992; 103: $1732-1738$

[12] Boeckxstaens GE, Zaninotto G, Richter JE. Achalasia. Lancet (London, England) 2014; 383: 83-93

[13] Tung HN, Schulze-Delrieu K, Shirazi S et al. Hypertrophic smooth muscle in the partially obstructed opossum esophagus. The model: histological and ultrastructural observations. Gastroenterology 1991; 100: $853-864$

[14] Gabella G. Hypertrophy of intestinal smooth muscle. Cell Tissue Res 1975; 163: 199-214

[15] Ferguson TB, Woodbury JD, Roper CL et al. Giant muscular hypertrophy of the esophagus. Ann Thorac Surg 1969; 8: 209-218

[16] Friesen DL, Henderson RD, Hanna W. Ultrastructure of the esophageal muscle in achalasia and diffuse esophageal spasm. Am J Clin Pathol 1983; 79: 319-325

[17] Mittal RK, Kassab G, Puckett JL et al. Hypertrophy of the muscularis propria of the lower esophageal sphincter and the body of the esophagus in patients with primary motility disorders of the esophagus. Am J Gastroenterol 2003; 98: 1705-1712

[18] Sotoudehmanesh R, Mikaeli J, Daneshpajooh M et al. Endoscopic ultrasonography findings in patients with achalasia. Esophagus 2011; 8: $187-190$

[19] Goldblum JR, Whyte RI, Orringer MB et al. Achalasia. A morphologic study of 42 resected specimens. Am J Surg Pathol 1994; 18: 327 - 337

[20] Goldblum JR, Rice TW, Richter JE. Histopathologic features in esophagomyotomy specimens from patients with achalasia. Gastroenterology 1996; 111: $648-654$

[21] Van Dam J. Endosonographic evaluation of the patient with achalasia. Endoscopy 1998; 30: (Suppl. 01): A48 - 50

[22] Van Dam J, Falk GW, Sivak MV Jr et al. Endosonographic evaluation of the patient with achalasia: appearance of the esophagus using the echoendoscope. Endoscopy 1995; 27: 185-190

[23] Miller LS, Schiano TD. The use of high frequency endoscopic ultrasonography probes in the evaluation of achalasia. Gastrointest Endosc Clin North Am 1995; 5: 635-647 


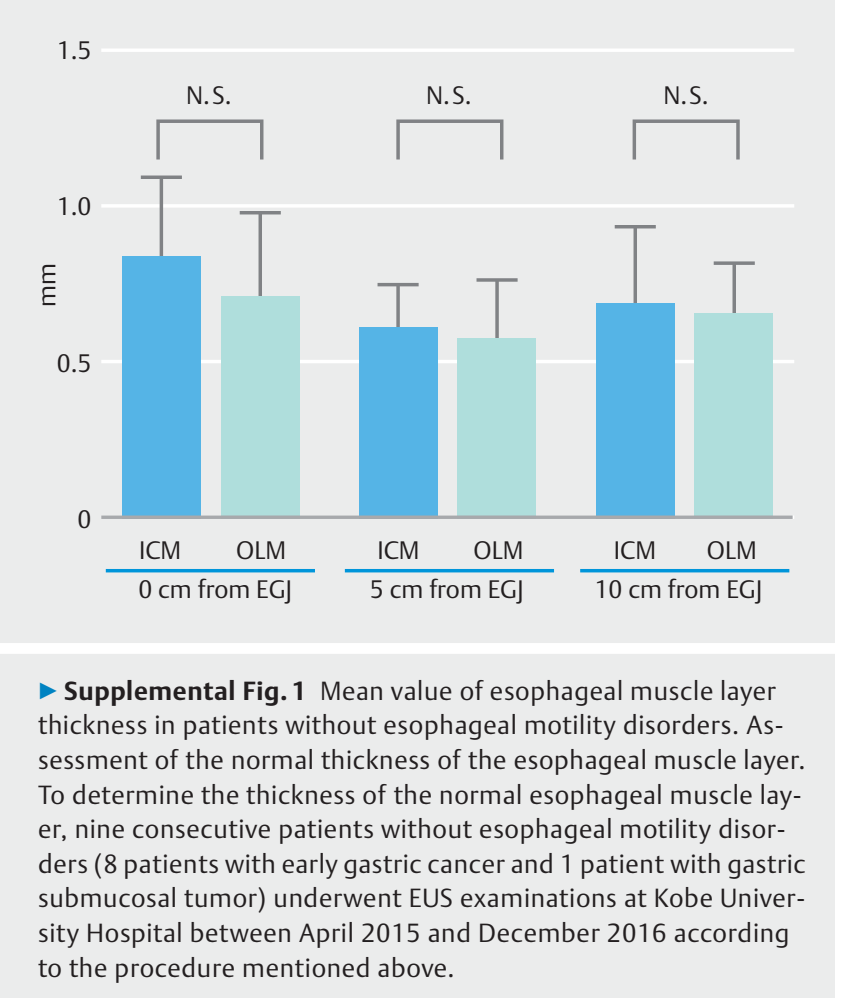

